REF - ISSN 1808-0804 Vol. VI (2), 36 - 61, 2009

\title{
PROPRIEDADES QUÍMICAS E FARMACOLÓGICAS DO LICOPENO
}

\author{
Chemical and pharmacological properties of lycopene
}

\section{Alex Manoel da Silva ${ }^{1,2}$; Valeria Cristina Schneider ${ }^{1,3}$; Cíntia Alessandra Matiucci Pereira ${ }^{1,4 *}$}

\author{
${ }^{1}$ Centro Universitário Central Paulista (UNICEP), Rua Miguel Petroni, 5111, \\ 13563-470 São Carlos-SP, Brasil. \\ 1,2 Graduando do Curso de Farmácia do Centro Universitário Central Paulista (UNICEP) \\ 1,3 Graduanda do Curso de Nutrição do Centro Universitário Central Paulista (UNICEP) \\ 1,4 Professora Doutora dos Cursos de Farmácia e Nutrição do Centro Universitário Central \\ Paulista (UNICEP)
}

*Autor para correspondência: cmatiucci@gmail.com

Recebido em 12/03/2009 - Aceito em 07/04/2009

RESUMO: O licopeno, pigmento lipossolúvel de coloração avermelhada, está dentre os mais de 600 carotenóides existentes e atualmente tem atraído bastante interesse devido a algumas propriedades farmacológicas relacionadas à saúde humana. Definido quimicamente por uma estrutura acíclica com 40 átomos de carbono, o licopeno possui 11 duplas ligações conjugadas e 2 duplas ligações não conjugadas com conformação linear em all-trans, sendo muito eficiente no seqüestro de oxigênio singlete e radicais de peroxil tendo com isso poderosa ação antioxidante. O licopeno está presente em altos níveis no plasma e tecidos humanos com grande variação na sua distribuição, podendo ser encontrado no fígado, pulmão, mama, próstata e pele. A função antioxidante do licopeno é associada aos efeitos das dietas ricas em alimentos fontes (tomate, goiaba vermelha, melancia, mamão e pitanga) na contribuição da redução dos riscos da ocorrência de câncer de próstata e mama, além de estudos na atuação contra o câncer de esôfago, gástrico, pulmão e benefícios para câncer de pâncreas, cólon, reto, cavidade oral e cervical. Além disso, são relatados casos em que o consumo de licopeno está sendo inversamente associado ao risco de infarto do miocárdio e outras doenças cardiovasculares. Vários fatores podem interferir na biodisponibilidade do licopeno, 
dentre eles a quantidade de licopeno no alimento fonte, absorção intestinal, formas de apresentação, presença da matriz alimentar, presença de outros nutrientes na refeição, ingestão de drogas, processamento do alimento, além da individualidade biológica e do estado nutricional do indivíduo. O licopeno encontra-se em maior quantidade na casca dos alimentos, aumentando consideravelmente durante o seu amadurecimento. A quantidade de licopeno em produtos processados depende da composição do alimento, da origem e das condições de processamento.

PALAVRAS CHAVE: carotenóides, antioxidantes, alimentos funcionais.

ABSTRACT: Lycopene is a bright red pigment found in a range of more than 600 carotenoids. Currently, such pigment has been in evidence due to some pharmacological properties that could bring some benefits to human health. The chemical structure of lycopene is characterized by an acyclic structure containing both 11 conjugated double bounds and 2 non-conjugated double bounds with all-trans stable form. It has a structure with 40 highly unsaturated and non-polar atoms of carbon, being very efficient as singlet oxygen and peroxyl radicals quencher, what turns it into a very powerful antioxidant. The lycopene is highly found in plasma and tissues with a widespread distribution (liver, lung, breast, prostate and skin). The antioxidant function of lycopene is associated with the effects of foodborne diets in fruits and vegetables as tomatoes, red guava, watermelon, papaya and pitanga (a kind of fleshy red berry) contributing not only to reducing the risk of breast and prostate cancer but also acting against esophagus, stomach, lung cancer and benefiting pancreatic, colorectal, oral and cervical cancer. Furthermore, cases have been reported inversely associating the consumption of lycopene with both the risk of myocardial infarction and other cardiovascular diseases. Several factors can interfere with the bioavailability of lycopene, such as the amount of lycopene in foodborne, the intestinal absorption, the forms of presentation, the presence of the food matrix, the presence of other nutrients in the meal, drug ingestion, food processing, besides the individuality of the biological and nutritional status of the individual. The lycopene can be found in larger quantities in fruit peel, increasing considerably during its ripening. The amount of lycopene in processed products depends both on the foodborne composition and the food-processing conditions.

KEYWORDS: carotenoids, antioxidants, functional foods. 


\section{INTRODUÇÃO}

Atualmente, a sociedade moderna mostra-se cada vez mais complexa, com intensas modificações nos padrões de morbi-mortalidade e com inúmeros fatores que estão afetando a qualidade de vida, como sintomas de cansaço, depressão e irritação, estresse e doenças crônicas não transmissíveis, como câncer e doenças coronarianas.

A incidência de morte devido a acidentes cardiovasculares, câncer, acidente vascular cerebral, arteriosclerose, enfermidades hepáticas, dentre outros, pode ser minimizada através de alguns compostos bioativos e substâncias presentes em determinados alimentos, os chamados alimentos funcionais $e$ os nutracêuticos (MORAES \& COLLA, 2006).

Segundo SOUZA et al. (2003), os alimentos funcionais devem apresentar propriedades benéficas além das nutricionais básicas, sendo apresentados na forma de alimentos comuns. São consumidos em dietas convencionais, mas demonstram capacidade de regular funções corporais de forma a auxiliar na proteção contra doenças como hipertensão, diabetes, câncer, osteoporose e coronariopatias.

O termo nutracêutico define uma ampla variedade de alimentos e componentes alimentícios com apelo médico ou de saúde, sua ação varia do suprimento de minerais e vitaminas essenciais até a proteção contra várias doenças infecciosas, tais produtos podem abranger nutrientes isolados, suplementos dietéticos e dietas para alimentos geneticamente planejados, alimentos funcionais, produtos herbais e alimentos processados (KWAK \& JUKES, 2001; HUNGENHOLTZ \& SMID, 2002).

O consumo regular desses alimentos e nutrientes considerados funcionais pode ser uma alternativa para conter o avanço dessas doenças. Existem muitos compostos e substâncias com propriedades funcionais, como os carotenos, em especial o licopeno, no qual há indícios que possua capacidade de exercer uma ação protetora específica contra o desenvolvimento de certos tipos de câncer e doenças coronárias (BURRI, 2002). Em 2005, o Ministério da Saúde reconheceu a ação benéfica do licopeno e aprovou a alegação de propriedade funcional para este composto, associandoo ao combate de radicais livres. De acordo com a ANVISA (1999), alegação de propriedade funcional é aquela relativa ao papel metabólico ou fisiológico que o nutriente ou não-nutriente tem no crescimento, desenvolvimento, na manutenção e em outras funções normais do organismo humano.

Esta revisão bibliográfica tem por objetivo central formular uma melhor compreensão dos benefícios farmacológicos do carotenóide licopeno, como a atuação antioxidante e biodisponibilidade, além de sua estrutura química. 


\section{Radicais Livres e Estresse Oxidativo}

O estresse oxidativo induzido por espécies reativas de oxigênio é um dos maiores focos da pesquisa recente relacionada ao câncer e a doenças cardiovasculares. Embora pareça mais fácil entender a ligação de radicais livres com o câncer devido aos danos causados ao DNA, é preciso lembrar que as doenças cardiovasculares também têm na oxidação de moléculas a sua origem. O primeiro passo no desenvolvimento destas doenças se dá com a oxidação de lipoproteínas de baixa densidade (LDL), com sua posterior absorção por macrófagos na parede das artérias. $\mathrm{O}$ acúmulo desse material causa a formação de células "espumosas" (foam cells) e o surgimento de placas ateroscleróticas, que podem resultar em acidentes cardiovasculares. Dessa forma, o estudo do licopeno se mostra de grande importância, uma vez que seu papel como antioxidante tem sido comprovado por diversos estudos (FERREIRA \& MATSUBARA, 1997; AGARWAL \& RAO, 2000; RAO, 2002; MACHADO, 2005).

A expressão radical livre é muito utilizada para designar qualquer átomo ou molécula orgânica ou inorgânica com existência independente, contendo um ou mais elétrons não pareados, em seus orbitais externos. Isto determina uma atração para um campo magnético, o que pode torná-lo altamente reativo, capaz de reagir com qualquer composto situado próximo à sua órbita externa, passando a ter uma função oxidante ou redutora de elétrons (HALLIWELL \& GUTTERIDGE, 1999a).

Sendo moléculas muito instáveis, os radicais livres possuem meia-vida curta e são quimicamente muito reativos. Muitos radicais livres são produzidos por oxidação durante o metabolismo normal do corpo humano. Quando os elétrons são transferidos dos catalisadores para 0 oxigênio, novas espécies de oxigênio são formadas. Assim, cada radical livre pode começar um processo destrutivo de remoção de elétrons de compostos estáveis e formar vários outros radicais livres (INSERRA et al., 1997).

O oxigênio pode dar origem a diversas espécies reativas que incluem radicais livres como o superóxido $\left(\mathrm{O}_{2}{ }^{-}\right)$, a hidroxila $\left(\mathrm{OH}{ }^{-}\right)$, o hidroperóxido $\left(\mathrm{HO}_{2}{ }^{\bullet}\right)$, o óxido nítrico ( $\mathrm{NO}{ }^{\circ}$ ), o dióxido de nitrogênio $\left(\mathrm{NO}_{2}{ }^{\circ}\right)$ e também espécies não radicalares.como o peróxido de hidrogênio $\left(\mathrm{H}_{2} \mathrm{O}_{2}\right)$ (FERREIRA \& MATSUBARA, 1997). $\mathrm{O}$ radical hidroxila $\left(\mathrm{OH}^{-}{ }^{-}\right)$é o mais reativo na indução de lesões nas moléculas celulares e o peróxido de hidrogênio $\left(\mathrm{H}_{2} \mathrm{O}_{2}\right)$, apesar de não ser radical livre, é capaz de atravessar a membrana nuclear e induzir danos na molécula de DNA (SHAMI \& MOREIRA 2004).

Os radicais livres podem ser gerados no citoplasma, nas mitocôndrias ou na membrana, a partir de dois sistemas enzimáticos, o sistema oxidativo de $\mathrm{NADP}^{+} / \mathrm{NADP}^{+} \mathrm{H}^{+}$e o da mieloperoxidade, sendo seu alvo celular (proteínas, lipídeos, carboidratos e DNA) relacionado ao seu 
sítio de formação (ANDERSON, 1996; YU \& ANDERSON, 1997)

Embora uma pequena quantidade de radicais livres seja necessária para a manutenção de diversos processos fisiológicos, a sua produção excessiva pode conduzir a diversas formas de dano celular e a sua cronicidade pode muitas vezes estar envolvida com a etiogênese ou com o desenvolvimento de numerosas doenças (SPEISKY \& JIMÉNEZ, 2000; SHAMI \& MOREIRA 2004).

Outras fontes de radicais livres são inflamações, exercícios físicos intensos, exposição a certos compostos químicos, radiação, luz ultravioleta, cigarro, álcool, ar poluído, excesso de cálcio livre, excesso de ferro e dieta rica em gorduras (INSERRA et al., 1997).

Quando os sistemas de defesa fisiológicos contra os radicais livres tornam-se insuficientes frente à sua excessiva produção, ocorre o chamado estresse oxidativo. $O$ estresse oxidativo é caracterizado por uma intensa sobrecarga de radicais livres, que pode ser extremamente lesiva às estruturas celulares, com conseqüências tumorogênicas. A lesão oxidativa de material genético, também possui estreita relação com a tumorogênese, e pode ser utilizada como indicador do efeito dos carotenóides sobre o desenvolvimento do câncer (GOMES, 2007).

Tanto o estresse oxidativo agudo como o crônico tem sido associado a um grande número de doenças degenerativas como artrite, aterosclerose, diabetes, catarata, esclerose múltipla, inflamações crônicas, disfunção cerebral, cardiopatias, enfisema, envelhecimento, câncer e doenças do sistema imune, além de Mal de Parkinson, acidentes vasculares cerebrais e doença de Alzheimer (FERREIRA \& MATSUBARA, 1997; BIANCHI \& ANTUNES, 1999).

As reações de eliminação de radicais livres não são favorecidas em condições fisiológicas normais, devido às suas baixas concentrações. Assim, a principal forma de eliminação destas espécies e, portanto, da interrupção de reações em cadeias propagadas por elas depende da ação de compostos denominados antioxidantes (CERQUEIRA et al, 2007).

\section{Antioxidantes e Mecanismo de Proteção}

Para evitar danos causados por radicais livres, o organismo desenvolveu vários mecanismos de defesa, isto é, potenciais de neutralização das ações dos radicais livres, os chamados antioxidantes. Estas substâncias podem ser tanto de origem endógena, como enzimas produzidas pelo próprio organismo exposto, ou exógenas, sendo obtidas pela alimentação. Os antioxidantes podem agir diretamente na neutralização da ação dos radicais livres ou participar indiretamente de sistemas enzimáticos com essa função (MACHADO, 2005).

HALLIWELL \& GUTTERIDGE (1999a) definiram antioxidante como uma substância presente em concentrações baixas, comparadas às concentrações do 
substrato oxidante, que previne significativamente ou atrasa a oxidação de substratos susceptíveis. Os principais mecanismos de ação de compostos antioxidantes incluem captadores de radicais e supressores de estados excitados; sistemas catalíticos que neutralizam ou eliminam os radicais livres e a ligação de íons metálicos a proteínas, o que os torna indisponíveis para a produção de espécies oxidantes (CERQUEIRA et al., 2007).

Entre os principais antioxidantes encontrados no plasma humano estão proteínas/peptídeos com grupamento tiol (SH) (800-1000 $\mu \mathrm{mol} / \mathrm{L})$, sendo a albumina a principal representante; ácido úrico (150-400 $\mu \mathrm{mol} / \mathrm{L})$; ácido ascórbico (30-150 $\mu \mathrm{mol} / \mathrm{L})$; tocoferol (20-50 $\mu \mathrm{mol} / \mathrm{L}$ ) e carotenóides $(0,08-3 \mu \mathrm{mol} / \mathrm{L}$ ) (YEUM et al., 2004).

\section{Segundo BIANCHI \& ANTUNES} (1999), os antioxidantes atuam em diferentes níveis na proteção dos organismos:

a) Primeiramente, impedem sua formação, principalmente pela inibição das reações em cadeia com o ferro e o cobre.

b) Interceptam os radicais livres gerados pelo metabolismo celular ou por fontes exógenas, impedindo o ataque sobre os lipídeos, os aminoácidos das proteínas, a dupla ligação dos ácidos graxos poliinsaturados e as bases do DNA, evitando a formação de lesões e perda da integridade celular. Os antioxidantes obtidos da dieta, tais como os flavonóides e carotenóides são extremamente importantes na intercepção dos radicais livres.

c) Reparação das lesões causadas pelos radicais, processo relacionado com a remoção de danos da molécula de DNA e a reconstituição das membranas celulares danificadas. As bases oxidadas do DNA são corrigidas por mecanismo de reparo por excisão de bases, que atua nas modificações causadas por agentes endógenos. O reparo por excisão de nucleotídeos é um dos mais importantes devido a sua versatilidade em operar, principalmente, em danos provocados por agentes exógenos que causam distorção da dupla-hélice do DNA. O reparo do emparelhamento errôneo (mismatch repair) corrige pares errôneos de bases e alças desemparelhadas no DNA, eventualmente introduzidos por erros de replicação, ou lesões que interfiram com a atividade replicativa das DNA polimerases (GUARNIERI et al., 2008; BERRA et al., 2006).

d) Em algumas situações pode ocorrer uma adaptação do organismo em resposta a geração desses radicais com o aumento da síntese de enzimas antioxidantes. A toxicidade do oxigênio nas células aeróbias decorre da formação de espécies reativas de oxigênio que podem interagir com diversas biomoléculas, que com o objetivo de se estabilizarem lesam diferentes estruturas celulares. Em condições normais, a concentração destas espécies dentro das células é extremamente baixa pelo fato de existirem enzimas antioxidantes que as removem, ou 
impedem sua formação. Estes radicais tendem a ser eliminados do organismo pelo conjunto das enzimas glutationa peroxidase, glutationa redutase, superóxido dismutase e catalase. A superóxido dismutase, que depende de $\mathrm{Cu}^{2+}$ e $\mathrm{Zn}^{2+}$ como cofatores, promove a dismutação do radical superóxido em peróxido de hidrogênio e oxigênio e a catalase converte peróxido de hidrogênio em água e oxigênio molecular (HALLIWELL \& GUTTERIDGE, 1999b). Dos componentes não-enzimáticos da defesa antioxidante destacam-se alguns minerais (cobre, manganês, zinco, selênio e ferro), vitaminas (ácido ascórbico, vitamina E, vitamina A), carotenóides (beta-caroteno, licopeno e luteína), bioflavonóides (genisteína, quercetina) e taninos (catequinas) (PAPAS, 1999).

\section{Carotenóides}

Os carotenóides formam um dos grupos de pigmentos mais difundidos na natureza, sendo responsáveis pela coloração amarela, laranja e vermelha de grande número de frutas, folhas e algumas flores (BOBBIO \& BOBBIO, 2001).

Esses pigmentos naturais são sintetizados por plantas e microrganismos, sendo componentes essenciais dos alimentos. Os carotenóides têm como função primária absorver luz durante a fotossíntese em plantas ou fotoproteção de microrganismos. A estrutura química é responsável pela coloração e por diversas funções biológicas. Juntamente com as vitaminas são as substâncias mais investigadas como agentes

quimiopreventivos, funcionando como antioxidantes em sistemas biológicos (SHAMI \& MOREIRA, 2004; AUGUSTI, 2007).

A importância dos carotenóides não é somente atribuída à cor que eles conferem a algumas frutas e vegetais, mas também aos benefícios à saúde, tanto pela atividade pró-vitamínica $A$ que alguns destes compostos apresentam, como pelas suas ações antioxidante e imunomoduladora (DAVISON et al., 1993; ERDMAN，1999; SGARBIERI \& PACHECO, 1999; RODRIGUEZ-AMAYA, 2002).

A propriedade antioxidante destes compostos está relacionada à desativação de radicais livres e ao seqüestro do oxigênio singlete (forma mais reativa do oxigênio). A capacidade do carotenóide seqüestrar oxigênio singlete está ligada ao sistema de duplas ligações conjugadas (DiMASCIO et al., 1989). Eles removem os radicais peróxidos, modulam 0 metabolismo carcinogênico, inibem a proliferação celular, estimulam a comunicação entre células, e elevam a resposta imune (SHAMI \& MOREIRA, 2004).

Geralmente, são compostos de 40 átomos de carbono, tendo uma série de duplas ligações conjugadas, que constituem o cromóforo responsável pela absorção de luz na região do visível. Podem ser acíclicos ou ciclizados em uma ou ambas as extremidades. Sua estrutura é tetraterpenóide, constituída por oito unidades isoprenóides de cinco carbonos, 
ligadas de tal forma que a molécula é linear e simétrica, com a ordem invertida no centro. De acordo com o tipo e teor de carotenóides, surgem as várias cores características de muitos alimentos (RODRIGUEZ-AMAYA，2002; PORCU, 2004).

Existem, aproximadamente, 600 carotenóides encontrados na natureza, os quais são constituídos por dois grandes grupos, denominados: Carotenos, que consistem em hidrocarbonetos puros e Xantofilas, hidrocarbonetos que possuem grupos funcionais oxigenados. Desses, 40 podem ser encontrados nos alimentos e, como resultado de uma absorção seletiva do trato gastrintestinal, apenas 14 carotenóides são biodisponíveis, biodisponibilidade que se apresenta de forma quase ilimitada. Entre esses se encontram o beta-caroteno, o alfacaroteno, a luteína, a zeaxantina e o licopeno (KHACHIK et al., 1991; PARKER et al., 1999; HAEGELE et al., 2000).

Os mamíferos não estão bioquimicamente capacitados para a biossíntese de carotenóides, mas podem acumular e/ou converter precursores que obtêm da dieta (por exemplo, a conversão de beta-caroteno em vitamina $A$ ). No plasma humano, predominam 0 betacaroteno e o licopeno (FONTANA, 1997).

Os carotenóides apresentam boa estabilidade na faixa de $\mathrm{pH}$ dos alimentos que os contêm e não são afetados por substâncias redutoras. Contudo, apresentam suscetibilidade à isomerização e degradação oxidativa, limitada solubilidade em óleos e insolubilidade em água. Eles são encontrados na natureza como soluções oleosas, dispersões coloidais ou complexados com proteínas, assim ocorrem tanto em meio lipídico quanto aquoso. Os carotenóides são, portanto, comercializados como suspensões oleosas para alimentos a base de óleo, ou como emulsões ou preparações coloidais dispersíveis em alimentos a base de água. Desta forma, os carotenóides são fisicamente estabilizados (RODRIGUEZAMAYA, 2002).

A composição dos carotenóides de um determinado alimento pode variar devido a diversos fatores, como o cultivar ou a variedade do vegetal, parte da planta analisada, estágio de maturação, condições pós-colheita, localização geográfica do cultivo (efeito climático) e modo de preparo para o consumo (RODRIGUEZ-AMAYA, 1999).

\section{Licopeno}

O licopeno (Figura 1) é um dos 600 pigmentos carotenóides encontrados na natureza e um dos 25 encontrados no plasma e tecidos humanos (MORITZ; TRAMONTE, 2006). Como carotenóide, o licopeno é um pigmento natural sintetizado por plantas e microorganismos, mas não por animais (MIRANDA, 2005; MACHADO, 2005). É um carotenóide sem a atividade pró-vitamina A e lipossolúvel.

É caracterizado por uma estrutura simétrica e acíclica de 40 carbornos, cuja massa molecular é de 536,85Da (RODRIGUEZ-AMAYA， 1999; SHI; 
PEREIRA, C. A. M. et al./Revista Eletrônica de Farmácia Vol 6(2), 36-61, 2009.42 MAGUER, 2000). É tido como o possui duas ligações duplas não carotenóide que possui a maior capacidade conjugadas, o que the oferece maior seqüestrante do oxigênio singlete, pois reatividade (ANGUELOVA \& WARTHESEN, além das 11 ligações duplas conjugadas 2000).

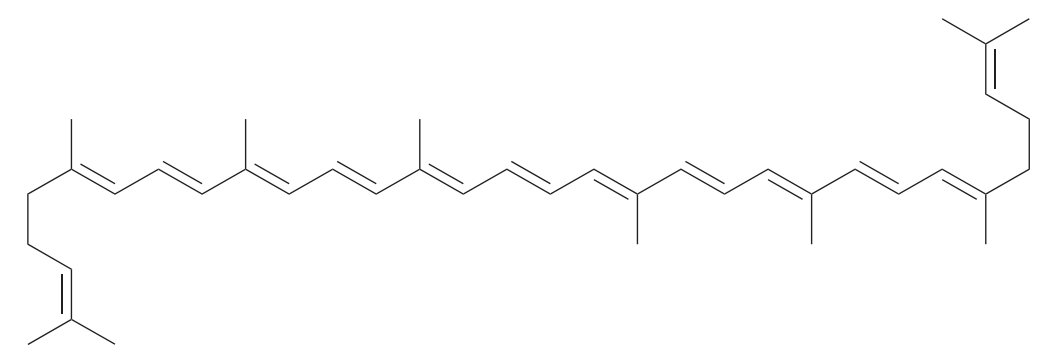

Figura 1. Estrutura química do licopeno

Segundo XIANQUAN et al. (2005), a fórmula molecular do licopeno é $\mathrm{C}_{40} \mathrm{H}_{56}$, sendo mais solúvel em clorofórmio, benzeno e outros solventes orgânicos do que em água.

Esse sistema de duplas ligações conjugadas constitui o cromóforo responsável pela sua habilidade de absorver luz na região visível, conseqüentemente pelo seu poder corante, sendo responsável pela coloração vermelho-alaranjada de vegetais nas quais está presente. Pelo menos sete duplas conjugadas são necessárias para que um carotenóide seja colorido. Quando o sistema conjugado é estendido, a cor também intensifica (RODRIGUEZ-AMAYA, 2002; NIIZU, 2003). Este polieno também sofre variações cis-trans por isomeria geométrica, induzida por luz, energia térmica ou reações químicas (Figura 2). 


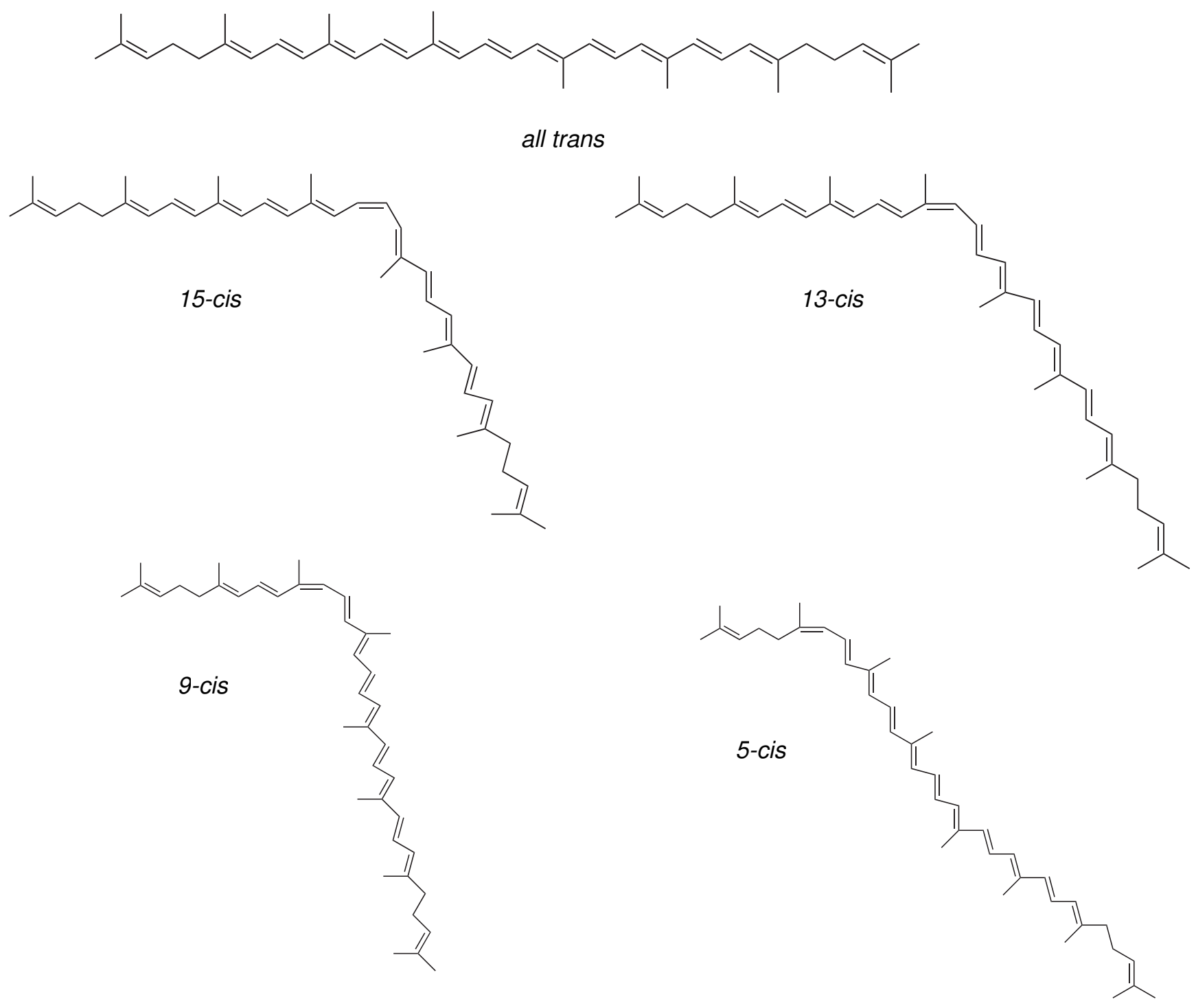

Figura 2. Estruturas de isômeros cis e trans do licopeno (AGARWAL \& RAO, 2000)

O licopeno é disponível, pela alimentação, através de uma lista não muito extensa de frutas e vegetais, ao contrário do que acontece com outros carotenóides (RAO \& AGARWAL, 2000). Acredita-se que 0 licopeno possa corresponder de $30 \%$ até $64 \%$ da ingestão total de carotenóides, o que equivale aproximadamente a $3,7 \mathrm{mg} / \mathrm{dia}$. As principais fontes de licopeno são o tomate, goiaba vermelha, melancia, mamão e pitanga (RODRIGUEZ-AMAYA, 2002;
NIIZU, 2003). Mais de $85 \%$ da ingestão de licopeno provém do consumo de tomates e derivados. O estado de maturação do tomate pode alterar a concentração do licopeno. A fruta in natura contém cerca de $30 \mathrm{mg}$ de licopeno/kg de fruta. Quantidades significativas de licopeno também foram encontrados em suco de tomate e catchup. A concentração de licopeno em frutas, vegetais e subprodutos do tomate, está descrita na Tabela 1. 
Tabela 1. Quantidade de licopeno em alguns alimentos fontes.

\section{ORIGEM}

DA

LICOPENO

REF.

FONTE AMOSTRA $(\boldsymbol{\mu g} / \mathrm{g})$

Goiaba

(Psidium guajava)
São Paulo

São Paulo

São Paulo

São Paulo

Bahia

São Paulo

$36 \pm 5$

$35 \pm 2$

Bahia

(Citrullus lanatus)

Pitanga

(Eugenia uniflora)
Pernambuco $\quad 73 \pm 1$

Paraná $\quad 14 \pm 5$

São Paulo

$$
71 \pm 9
$$

RODRIGUEZ-AMAYA, 1999

KIMURA \& RODRIGUEZ-AMAYA, 2002

PORCU, 2004

KIMURA \& RODRIGUEZ-AMAYA, 2002

\section{Tomate}

(Licopersicon

São Paulo $31 \pm 20$

TAVAREZ \& RODRIGUEZ-AMAYA, 1994

esculentum)

São Paulo

$35 \pm 10$

NIIZU, 2003

$$
\begin{gathered}
7,1 \pm 5,5 \text { (cis) } \\
\text { e } 62 \pm 8
\end{gathered}
$$

Suco de tomate

(trans)

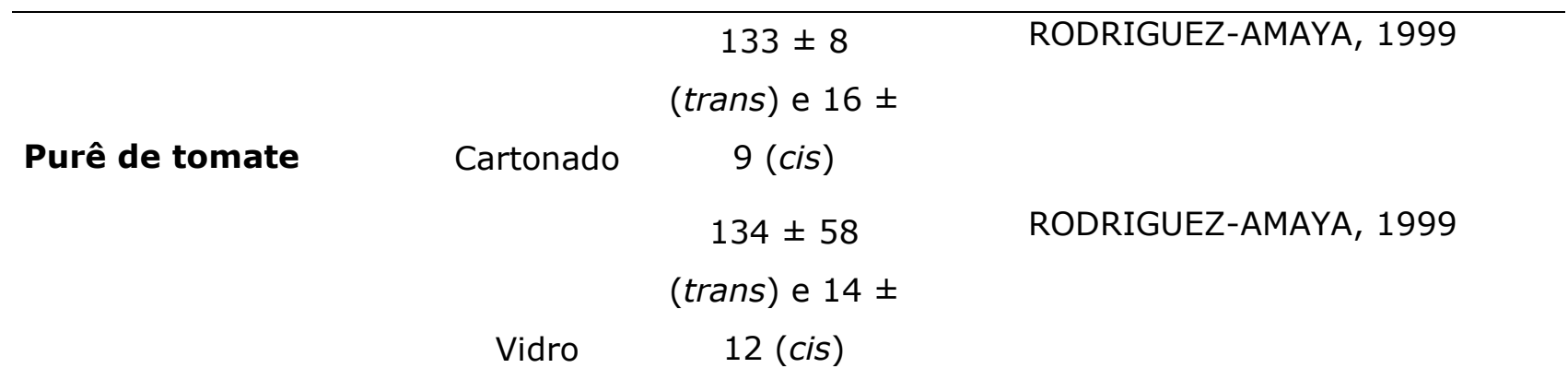




$$
114 \pm 89
$$

RODRIGUEZ-AMAYA, 1999

(trans) e $5,6 \pm$

Enlatado 2,4 (cis)

$170 \pm 61$

RODRIGUEZ-AMAYA, 1999

(trans) e $31 \pm$

Vidro 22 (cis)

$164 \pm 53 \quad$ RODRIGUEZ-AMAYA, 1999

(trans) e $21 \pm$

Tomate em pasta Enlatado 8 (cis)

$103 \pm 41$

RODRIGUEZ-AMAYA, 1999

(trans) e $10 \pm$

Catchup

2 (cis)

O licopeno encontrado em plantas está predominantemente na configuração trans, a forma termodinamicamente mais estável. Já no plasma humano, este composto se encontra em uma mistura isomérica contendo cerca de $50 \%$ do licopeno total na forma cis (RAO \& AGARWAL, 2000).

Apesar do licopeno estar presente nos alimentos, em sua maioria, na forma trans $(80 \%$ a $97 \%)$, parecem ser os cisisômeros a forma mais encontrada e a mais bem absorvida no corpo humano, devido ao seu comprimento reduzido e sua melhor solubilidade nas micelas, com isso, os isômeros cis de licopeno têm menor dificuldade em se mover através de membranas plasmáticas (TIUZZI, 2008).

O licopeno está presente no plasma e tecidos humanos com grande variação na sua distribuição (MORITZ \& TRAMONTE, 2006). Um aspecto importante do licopeno é a sua biodisponibilidade, que é relacionada com o fato da fração ingerida do carotenóide ser viável para uso em condições fisiológicas normais ou em condições de estocagem. A assimilação envolve absorção, transporte e metabolização (MIRANDA, 2005). A estrutura $e$ as propriedades física e química do licopeno presente nos alimentos irão determinar 0 seu aproveitamento pelo organismo.

\section{Absorção e transporte}

O processo de absorção ocorre de forma passiva, ou seja, sem gasto de energia, mas pouco se sabe sobre o aproveitamento do licopeno no interior da mucosa. BOILEAU et al. (2002) sugerem que o licopeno seja transportado entre as células por proteínas específicas ou migre agregado a gotas lipídicas. No enterócito, - licopeno não é transformado em vitamina A, como ocorre com outros carotenóides, mas metabólitos oxidativos do licopeno têm sido encontrados no soro humano, embora pouco se saiba sobre os 
locais e mecanismos envolvidos em sua formação. O licopeno sai do enterócito carreado por quilomícrons que, pela ação da enzima lipase lipoprotéica, vão sendo retirados e absorvidos de forma passiva por vários tecidos, incluindo os adrenais, renais, adiposos, esplênicos, dos pulmões e dos órgãos reprodutivos. Esses carotenóides podem se acumular no fígado ou ser envolvidos pela lipoproteína de densidade muita baixa (VLDL) e levados novamente ao sangue.

O licopeno ingerido na forma natural (trans) é pouco absorvido, mas WILLCOX et al. (2003) demonstraram que o processamento térmico melhora a biodisponibilidade por ajudar no rompimento da parede celular e extração .

Os isômeros livres de licopeno provenientes de fontes dietéticas são incorporados e misturados dentro das micelas, assim, são absorvidos pela borda em escova da mucosa intestinal, incorporados aos quilomícrons. Pela ação da lipase lipoprotéica que atua nos quilomícrons, o licopeno e outros carotenóides são secretados passivamente para vários órgãos e tecidos, dentre eles, adrenais, rim, células adiposas, baço, pulmão e órgãos reprodutores. Não se tem muito conhecimento sobre o transporte e metabolismo dos isômeros de licopeno e o mecanismo pelos quais eles são incorporados dentro dos quilomícrons (BOILEAU et al., 2002).

\section{Metabolização}

De acordo com KHACHICK et al. (2002), a oxidação do licopeno é um processo complexo. O processo oxidativo ocorre naturalmente no fruto cru ou durante o processamento térmico, além de ocorrer in vivo como parte do metabolismo normal do carotenóide. Inicialmente, o licopeno é oxidado nas posições 1 e 5, originando licopeno 1,2 epóxido e licopeno 5,6-epóxido, respectivamente. Assim, o potencial benéfico do licopeno pode ser mediado por seus metabólitos (AUGUSTI, 2007).

\section{Biodisponibilidade}

A biodisponibilidade dos constituintes do alimento é um processo complexo, que envolve digestão, captação intestinal, absorção, distribuição para os tecidos e sua utilização por eles. Existem vários fatores que podem interferir na biodisponibilidade dos carotenóides, como: matriz alimentar; forma isomérica do licopeno; quantidade e tipo de gordura dietética; processo de absorção; interações entre os carotenóides; presença de fibra alimentar e processamento de alimentos fontes (BRAMLEY, 2000; MORITZ \& TRAMONTE, 2006; CLARETO, 2007).

A biodisponibilidade do licopeno parece estar relacionada às formas isoméricas apresentadas. $\mathrm{O} \mathrm{pH}$ ácido do estômago parece contribuir, em pequena parte, na transformação de all-trans para cis-isômeros de licopeno. Além disso, temse sugerido que isômeros lineares all-trans podem, prontamente, agregar-se dentro 
do intestino e formar cristais, reduzindo grandemente sua absorção pelas micelas (BOILEAU et al, 1999).

O efeito do tratamento térmico é importante para a disponibilidade de licopeno, que tem o rompimento de sua membrana facilitado, o que proporciona a conversão do licopeno da forma trans para a cis, aumentando sua solubilidade e consequentemente sua disponibilidade (STAHL \& SIES, 1992; UNLU et al., 2007). O licopeno encontrado em tomates frescos aparece predominantemente na configuração trans, mas é o isômero cis que é encontrado no plasma e tecidos humano.

Além da disponibilidade aumentada pelo aquecimento, a ingestão de gorduras aumenta a biodisponibilidade e a absorção do licopeno. Por exemplo, o consumo de molho de tomate aumenta as concentrações séricas de licopeno em taxas maiores do que o consumo de tomates crus ou suco de tomate fresco. A ingestão de molho de tomate cozido em óleo resultou em um aumento de 2 a 3 vezes da concentração sérica de licopeno um dia após sua ingestão, mas nenhuma alteração ocorreu quando se administrou suco de tomate fresco. A absorção de licopeno, portanto, parece ser maior em produtos que utilizam tomates cozidos, e influenciada pela quantidade de gordura da refeição (SHAMI \& MOREIRA, 2004; MORITZ \& TRAMONTE, 2006).

Além disso, algumas fibras, como a pectina, podem reduzir a absorção de licopeno devido ao aumento da viscosidade. Alguns carotenóides também podem afetar a biodisponibilidade do licopeno, como, por exemplo, a luteína e o betacaroteno, pois ocorre uma competição durante a absorção intestinal do licopeno (MORITZ \& TRAMONTE, 2006).

\section{Propriedades Farmacológicas do Licopeno e suas Funções no Organismo Humano}

Apesar de não ser considerado um nutriente essencial, pesquisas têm demonstrado que o licopeno pode trazer diversos benefícios para a saúde humana (LEVY \& SHARONI, 2004).

A função antioxidante tem sido muito investigada e possivelmente está associado ao efeito das dietas ricas em licopeno. O licopeno dietético pode aumentar o estado do licopeno sérico contribuindo na redução dos riscos e da ocorrência de câncer de esôfago, gástrico, próstata, pulmão, além dos benefícios para câncer de pâncreas, cólon, reto, cavidade oral, seio e cervical (CLINTON, 1998; GIOVANNUCCI, 1999, CLARETO, 2007).

O consumo de licopeno também está sendo inversamente associado com risco de infarto do miocárdio (KRIS-ETHERTON et al., 2002). A oxidação da molécula de LDL é o passo inicial para o desenvolvimento do processo aterogênico e conseqüente doença coronária; embora exista um limite na evidência de que uma suplementação de licopeno possa reduzir os níveis de LDL-colesterol (ARGAWAL; RAO, 2000). Um possível mecanismo para o efeito protetor do licopeno contra 
doenças cardíacas é a inibição de uma enzima (HMGCoA redutase) que é importante na síntese do colesterol (AUGUSTI, 2007).

Alternativamente, alguns mecanismos não-antioxidantes podem ser, também, responsáveis pelos efeitos benéficos do licopeno. $\mathrm{O}$ aumento da concentração de licopeno no corpo pode regular funções de genes, melhorar a comunicação celular, modular a resposta hormonal e imune ou regular o metabolismo, diminuindo assim o risco para doenças crônicas (ARGAWAL \& RAO, 2000; AUGUSTI, 2005).

HADLEY et al. (2003), constataram que o consumo diário de produtos do tomate, contendo $15 \mathrm{mg}$ de licopeno, aliado a outros fitonutrientes do mesmo, aumentou significativamente a proteção às lipoproteínas do estresse oxidativo ex vivo. Estes resultados indicam que o licopeno absorvido de produtos de tomate atua como antioxidante in vivo (SERRA \& CAMPOS, 2006).

O interesse no licopeno e no seu potencial papel protetor sobre a carcinogênese deu início quando GIOVANNUCCI et al. (1999), demonstraram uma relação inversa entre a ingestão de licopeno e a incidência de câncer de próstata. O licopeno é encontrado na próstata humana, sugerindo a possibilidade biológica de um efeito direto deste carotenóide na função da próstata e na da carcinogênese (BOILEAU et al, 2000; SHAMI \& MOREIRA, 2004). Nenhum dos estudos analisados por
GIOVANNUCCI et al. (1999), indicou que o alto consumo ou alto nível de licopeno no sangue aumentaram consideravelmente $o$ risco de câncer em qualquer das localizações investigadas. A evidência benéfica foi maior para tumores de próstata, pulmão e estômago.

O mecanismo de ação do licopeno no câncer de próstata inclui inibição da proliferação celular, efeitos antiandrógenos e anticrescimento, aumento da comunicação intercelular através do aumento de junções do tipo gap entre as células e modulando a progressão do ciclo celular (OLSON, 1999; CAMPBELL et al., 2004; CANENE-ADAMS et al., 2005; SILER et al., 2005; TANG et al., 2005). A interação célula a célula via junções do tipo gap é considerada um fator fundamental na homeostase tecidual, sua alteração está associada com o fenótipo neoplásico (LIVNY et al., 2002).

TIUZZI (2008) observou que o risco para o desenvolvimento de câncer de próstata diminuiu significantemente em homens que consumiram maiores quantidades de produtos a base de tomate. Desta forma, alimentos ricos em licopeno passaram a ser utilizados nas intervenções dietéticas de pacientes com câncer de próstata.

LIVNY et al (2002) investigaram os efeitos do licopeno na proliferação de uma linhagem de células cancerosas estabelecidas, $K B-1$, e compararam-se com a cultura celular primária obtida da mucosa normal. O licopeno exerceu uma inibição significante sobre a proliferação de 
células $K B-1$, enquanto a mucosa oral normal não foi afetada. Concluiram-se que o licopeno é um quimiopreventivo promissor, bem como um agente antiproliferativo e anticarcinogênico.

Uma revisão bibliográfica efetuada por TIUZZI (2008), identificou métodos de prevenção e efeitos do licopeno sobre células cancerosas in vitro e em humanos. In vitro, o licopeno tem efeito antimetastático, sendo um agente antiproliferativo, anticarcinogênico, inibindo assim a adesão, invasão e a migração de células, o que pode reduzir a ocorrência ou a progressão do câncer de próstata. Já em humanos, ingestões elevadas de licopeno, particularmente produtos cozidos, estiveram associadas com aproximadamente 10 a $20 \%$ no risco de câncer de próstata; concentrações séricas e prostática de licopeno aumentaram, danos oxidativos do DNA no tecido da próstata reduziram em homens que consumiram licopeno através do molho de tomate precedendo a prostatectomia radical programada.

BOILEAU et al. (2003) concluiram que o consumo de tomates e produtos à base de tomate poderia reduzir o risco de desenvolvimento de diversos tipos de câncer. As evidências mais fortes foram para o câncer de pulmão, próstata e estômago. Os dados também sugeriram um risco reduzido de câncer de cavidade oral, esôfago, pâncreas, intestino grosso, reto, colo de útero e mama.

Uma associação inversa com o consumo de carotenóides, licopeno e alfa- caroteno, com o risco de câncer de pulmão foi observada por MICHAUD et al. (2000), sendo que quando avaliaram os fumantes, apenas o licopeno manteve-se associado à redução de risco de câncer de pulmão. Eles também apontam que um período de 4 a 8 anos de consumo de carotenóides (licopeno e alfa-caroteno) é indicado para maximizar a proteção antes da doença (MORAES, 2007).

Os dados in vivo dos efeitos do licopeno ainda são escassos. BASU \& IMRHAN (2006), em extensa revisão, avaliam os ensaios clínicos que já foram realizados sobre os efeitos da suplementação do licopeno, na forma de produtos de tomate ou licopeno purificado, no estresse oxidativo e carcinogênese. Os autores concluíram que o licopeno contribui para os efeitos estudados, mas o modo de atuação ainda precisa ser investigado. Estudos sobre a ação do licopeno in vivo traria grandes contribuições para correlações a respeito da biodisponibilidade em condições fisiológica e concentração plasmática ideal para atividade de proteção contra radicais livres e doenças associadas.

\section{Dosagem terapêutica de licopeno para produção efeitos anticarcinogênico e antimutagênico}

O licopeno, como os demais carotenóides, encontra-se em maiores quantidades na casca dos alimentos, aumentando consideravelmente durante 0 seu amadurecimento. Sua concentração é maior nos produtos alimentícios de regiões 
de climas quentes. A quantidade de licopeno em produtos processados depende da composição do alimento, da origem e das condições de processamento. Os níveis de licopeno nos produtos processados são geralmente maiores do que os encontrados em alimentos crus, dado que há concentração do produto no processamento (SHAMI \& MOREIRA, 2004; SERRA \& CAMPOS, 2006).

O tratamento térmico e a homogeneização mecânica do tomate aumentam a absorção do licopeno nos tecidos corporais. Porém, esse cozimento ou tratamento térmico, pode diminui alguns componentes benéficos, como os flavonóides, vitamina C e vitamina E. Essa melhoria da biodisponibilidade pode ocorrer devido à presença de lipídeos na dieta, à isomeração induzida pelo calor formando mais cis-isômeros e à presença de outros carotenóides, como o betacaroteno (WILLCOX et al., 2003).

A rotação de qualquer uma das 11 duplas ligações presentes no licopeno permite a formação de alguns isômeros cis-geométricos, os quais podem ter implicações relativas à ação biológica desse carotenóide. O tratamento térmico é responsável pela isomerização que ocorre durante o processo absortivo, alterando a configuração do licopeno de trans para cisisômeros. Apesar disso, essa modificação é considerada pequena (até $10 \%$ do alltrans) para o cis com o processamento térmico ou desidratação. Está claro que outros processos fisiológicos são responsáveis pela grande diferença da proporção cis e trans observada em alimentos e tecidos (BOILEAU et al., 2002).

A América Latina possui uma ampla variedade de alimentos com altas concentrações de diferentes carotenóides, sendo 0 licopeno 0 carotenóide predominante no mamão papaia, goiaba vermelha, pitanga, melancia e tomate (MORITZ \& TRAMONTE, 2006).

Ainda não há consenso sobre as quantidades de licopeno que devem ser consumidas para obter o efeito de redução de riscos de doenças (MORAES, 2007). No Canadá, de acordo com RAO et al. (1998), a média de ingestão de licopeno, verificada por meio de questionários de freqüência alimentar, foi de $25 \mathrm{mg}$ por dia, com $50 \%$ desta ingestão representada por tomates frescos. Considerando que os tomates frescos são menos biodisponíveis que os tomates processados, os autores concluíram que uma maior ingestão de tomates processados seria aconselhada (SHAMI \& MOREIRA, 2004). Desta forma, RAO \& AGARWAL (2000) sugerem que o valor de $35 \mathrm{mg} /$ dia seria uma ingestão média diária apropriada deste antioxidante.

A dosagem terapêutica de licopeno varia de 6 a $60 \mathrm{mg}$ diárias. As dosagens citadas na literatura incluem em torno de $6 \mathrm{mg}$ para a redução do risco de câncer de próstata. As mesmas $6 \mathrm{mg}$ para a redução do risco de câncer de pulmão em mulheres não fumantes e $12 \mathrm{mg}$ para homens não fumantes; $30 \mathrm{mg}$ para diminuir 0 crescimento de câncer de próstata e $60 \mathrm{mg}$ 
para redução da LDL colesterol (LYCOPENE, 2003). Observa-se que muitos estudos ainda devem ser desenvolvidos para esclarecer a recomendação diária necessária desse carotenóide, bem como os efeitos do licopeno no sistema imunológico.

\section{Licopeno sintético e suplementação}

O licopeno sintético parece ser equivalente ao licopeno natural em relação à sua biodisponibilidade e com semelhante conteúdo isomérico. Isso é observado no estudo realizado por HOPPE et al. (2003), no qual o licopeno sintético não apresentou modificação na biodisponibilidade, quando comparado ao licopeno natural. Nesse estudo, os autores suplementaram por 28 dias, 3 diferentes grupos, com 12 indivíduos cada, utilizando o licopeno sintético (15mg), licopeno natural (15mg) e placebo. A dose administrada resultou no aumento de duas a três vezes mais licopeno no soro, quando comparado ao grupo-placebo. O aumento na quantidade de licopeno foi similar para os grupos suplementados com licopeno sintético e natural (MORITZ \& TRAMONTE, 2006).

Segundo LEVY \& SHARONI (2004), a suplementação com licopeno não altera os níveis séricos, por algum mecanismo ainda desconhecido, os níveis plasmáticos de licopeno permaneceram relativamente normais após a suplementação, o que pode constituir uma válvula de segurança. Segundo ARAújo (2008), a suplementação de licopeno pode melhorar os parâmetros de dano oxidativo induzidos pela doença arterial coronariana e exercícios intensos, a suplementação de licopeno também tem foi associada com a redução da peroxidação lipídica.

Verificações das possibilidades anticarcinogênicas do licopeno devem ser tratadas com muita cautela, especialmente quando são traduzidas à população como recomendação, visto que melhores resultados têm sido atribuídos à ingestão de produtos derivados do tomate, os quais, muitas vezes, contêm excessivas quantidades de sódio. Logo, recomendações que visam à garantia de um ambiente bioquímico celular mais protegido contra agentes cancerígenos podem induzir à carcinogênese por outras vias; a partir, por exemplo, da agressão à mucosa gástrica provocada pelo excesso de sódio contido em molhos como, por exemplo, o catchup (subproduto do tomate) (TSUGANE, 2005).

Um estudo efetuado por SERRA \& CAMPOS (2006) apontou que na verdade não são os compostos isolados e ingeridos sob a forma de suplemento que podem diminuir o risco de câncer ou doença arterial, mas sim uma gama de nutrientes originários de fontes alimentares. 
PEREIRA, C. A. M. et al./Revista Eletrônica de Farmácia Vol 6(2), 36-61, 2009.

\section{CONCLUSÃO}

A presente revisão demonstrou o papel do licopeno na saúde humana, o qual está baseado na poderosa capacidade antioxidante. O seu efeito antioxidante dá-se devido a sua estrutura química, no qual fundamentam-se principalmente no sistema de duplas ligações conjugadas, tornando possível a captação de radicais livres. O licopeno, encontrado em tomates e seus sub-produtos processados, goiaba vermelha, mamão, melancia e pitanga, têm sua função importante para o câncer de próstata, sendo que os possíveis mecanismos de proteção são por intermédio do seqüestro de radicais livres, modulação do metabolismo do carcinoma e inibição da proliferação celular. Porém, muitos estudos ainda devem ser realizados para esclarecer: as principais funções deste carotenóides, a quantidade e/ou porções de alimentos fontes que devem ser consumidos diariamente, bem como os efeitos do licopeno voltado para redução do risco do desenvolvimento de doenças cardíacas. Além disso, conclui-se também que mais estudos devem ser desenvolvidos com relação à eficácia e a segurança de pílulas contendo somente licopeno.

\section{REFERÊNCIAS BIBLIOGRÁFICAS}

AGARWAL, S.; RAO, A. V. Tomato lycopene and its role in human health and chronic diseases. Canadian Medical Association Journal, v. 19, n. 6, p. 739-744, 2000.

AGÊNCIA NACIONAL DE VIGILÂNCIA SANITÁRIA. ANVISA. Resolução no 18, de 30 de abril de 1999. Aprova o Regulamento Técnico que Estabelece as Diretrizes Básicas para Análise e Comprovação de Propriedades Funcionais e ou de Saúde Alegadas em Rotulagem de Alimentos. Diário Oficial da República Federativa do Brasil. 03 nov. 1999. Disponível em:<http://e-legis.bvs.br/leisref/public/showAct.php?id=109>. Acesso em: 10 jan. 2009. 1999.

AGÊNCIA NACIONAL DE VIGILÂNCIA SANITÁRIA. ANVISA. Alimentos com Alegações de Propriedades Funcionais e ou de Saúde, Novos Alimentos/Ingredientes, Substâncias Bioativas e Probióticos. Disponível em <http://www.anvisa.gov.br/alimentos/comissoes/tecno.htm>. Acesso em: 10 jan. 2009. 2005.

ANDERSON, D. Antioxidant defences against reactive oxygen species causing genetic and other damage. Mutation Research, v.350, n.1, p.103-108, 1996. 
ANGUELOVA, T.; WARTHESEN, J. Degradation of lycopene, a-carotene, and $\beta$-carotene during lipid peroxidation. Journal of Food Science, v.65, n.1, p.71-75, 2000.

ARAUJO, M. C. Efeitos do exercício físico regular e suplementação de licopeno sobre marcadores de estresse oxidativo na doença arterial coronariana. 2008. 78f. Dissertação (Mestrado em Ciências da Saúde), Universidade do Extremo Sul Catarinense - UNESC, 2008.

AUGUSTI, P. R. Efeito dos carotenóides licopeno e astaxantina sobre danos renais induzidos por cloreto de mercúrio. 2007. 97f. Dissertação (Mestrado em Bioquímica e Toxicologia) Universidade Federal de Santa Maria (UFSM-RS), Rio Grande do Sul, 2007.

BASU, A.; IMRHAN, V. Tomatoes versus lycopene in oxidative stress and carcinogenesis: conclusions from clinical trials. European Journal of Clinical Nutrition, v.61, n.3, p. 295303, 2007.

BEAR, M. F.; CONNORS, B. W.; PARADISO, M. A. Neurociências, Desvendando o Sistema Nervoso. 2a ed, Ed. Artmed, Porto Alegre, 2002.

BERRA, C.M.; MENCK, C.F.M.; DI MASCIO, P. Estresse oxidativo, lesões no genoma e processos de sinalização no controle do ciclo celular. Química Nova, v.29, n.6, p.13401344, 2006.

BIANCHI, M. L. P.; ANTUNES, L. M. G. Radicais livres e os principais antioxidantes da dieta. Revista de Nutrição, v. 12, n. 2, p. 123-130, 1999.

BOBBIO, P. A; BOBBIO, F.O. Química do processamento de alimentos. 3. ed. São Paulo: Varela, 2001. 143p.

BOILEAU, A. C., et al. Cis-lycopene is more bioavailable than trans-lycopene in vitro and in vivo in lymph-cannulated ferrets. Journal of Nutrition; v. 129, n. 6, p. 1176-1181, 1999.

BOILEAU, T. W, et al. Prostate Carcinogenesis in $N$-methyl- $N$-nitrosourea (NMU)Testosterone-Treated Rats Fed Tomato Powder, Lycopene, or Energy-Restricted Diets. Journal of the National Cancer Institute, v. 95, n. 21, p.1578-1586, 2003. 
BOILEAU, T. W.; BOILEAU, A. M.; ERDMAN JR., J. W. Bioavailability of all-trans and cisisomers of lycopene. Experimental Biology and Medicine, v. 227, n. 10, p. 914-919, 2002.

BRAMLEY, P.M. Is lycopene beneficial to human helth? Phytochemistry. v.54, n.3, p. 233$236,2000$.

BURRI, B.J. Lycopene and Human Health. In: MESKIN, M.S.; BIDLAKK, W.R.; DAVIES, A.J.; OMAYE, S.T. Phytochemicals in Nutrition and Health. New York: CRC Press, 2002. p.157-168.

CAMPBELL, J.K. et al. Tomato phytochemicals and prostate cancer risk. Journal of Nutrition. v.134, supl.12, p. 3486S-3492S, 2004.

CANENE-ADAMS, K. et al. The tomato as a functional food. Journal of Nutrition. v. 135, n.5, p. 1226-1230, 2005.

CAVALCANTE, M. L. Composição de carotenóides e valor de vitamina A em pitanga (Eugenia uniflora) e acerola (Malpighia glaba L.). 85f. Dissertação (Mestrado) Faculdade de Engenharia de Alimentos, Universidade Estadual de Campinas, Campinas, 1991.

CerqueirA, F. M.; Medeiros, M. H. G.; AUGUSto, O. Antioxidantes dietéticos: controvérsias e perspectivas. Química Nova, v. 30, n. 2, p. 441-449, 2007.

CLARETO, S. S. Estudo da concentração de licopeno da polpa de goiaba utilizando o processo de microfltração. 2007. 173f. Dissertação (Doutorado em Tecnologia de Alimentos). Universidade Estadual de Campinas - UNICAMP, 2007.

CLINTON, S. K. Lycopene: chemistry, biology, and implications for human health and disease. Nutrition Reviews, v. 56, n.2, p. 35-51, 1998.

DAVISON, A.; ROESSEAU, E.; DUNN, B. Putative anticarcinogenic actions of carotenoids: nutritional implications. Canadian Journal of Physiology and Pharmacology, v.71, p. 732$745,1993$. 
DI MASCIO, P.; KAISER, S.; SIES, H. Lycopene as the most efficient biological carotenoid singlet oxygen quencher. Archives of Biochemistry and Biophysics. v.274, n.2, p. 532538, 1989.

ERDMAN Jr J.W. Variable bioavailability of carotenoids from vegetables. American Journal of Clinical Nutrition. v.70, n.2, p. 179-80, 1999.

FERREIRA, A. L. A.; MATSUBARA, L. S. Radicais Livres: conceitos, doenças relacionadas, sistema de defesa e estresse oxidativo. Revista da Associação Médica Brasileira, v. 43, n. 1, p. 61-68, 1997.

FONTANA, J. D., et al. Carotenóides Cores Atraentes e Ação Biológica. $11^{\circ}$ Prêmio $\begin{array}{lllll}\text { Paranaense } & \text { em } & \text { C\&T } & \text { Disponível em }\end{array}$ <http://www.herbario.com.br/dataherb06/1112carotenoid.htm>. Acesso em 04.out. 2008 .

GIOVANNUCCI, E. Tomatoes, tomato-based products, lycopene, and cancer: review of the epidemiologic literature. Journal of the National Cancer Institute, v.91, n.4, p. 317$331,1999$.

GUARNIERI, S.; LOFT, S.; RISO, P.; PORRINI, M.; RISOM, L.; POULSEN, H.E.; DRAGSTED, L.O.; MOLLER, P. DNA repair phenotype and dietary antioxidant supplementation. British Journal of Nutrition, v. 99, n.5, p. 1018-1024, 2008.

GOMES, F. S. Carotenóides: uma possível proteção contra o desenvolvimento do câncer. Revista de Nutrição, v. 20, n. 5, p. 237-248, 2007.

HADLEY, C. W., et al. Tomatoes, Lycopene, and Prostate Cancer: Progress and Promise. Experimental Biology and Medicine, v. 227, p.869-880, 2002.

HAEGELE, A. D. et al. Plasma xanthophyll carotenoids correlate inversely with indices of oxidative DNA damage and lipid peroxidation. Cancer Epidemiology Biomarkers \& Prevetion. v.9, n.4, p. 421-425, 2000.

HALLIWELL, B., GUTTERDGE, J.M.C. The chemistry of free radicals and, related 'reactive species'. In: Free radicals in biology and medicine. 3rd ed. Oxford: Clarenton Press; 1999a. p.36-104. 
PEREIRA, C. A. M. et al./Revista Eletrônica de Farmácia Vol 6(2), 36-61, 2009.

HALLIWELL, B., GUTTERDGE, J.M.C. Antioxidant defences. In: Free radicals in biology and medicine. 3rd ed. Oxford: Clarenton Press; 1999b. p.105-148.

HOPPE, P.P. et al. Synthetic and tomato-based lycopene have identical bioavailability in humans. European Journal of Nutrition. v.42, n.5, p.272-278, 2003.

HUNGENHOLTZ, J.; SMID, E. J. Nutraceutical production with food-grade microorganisms. Current Opinion in Biotechnology. v. 13, p. 497-507, 2002.

INSERRA, P.F.; ARDESTANI, S.K.; WATSON, R.R.; Antioxidants and immune function. In: GAREWELL, H.S. (ed.) Antioxidants and disease prevention. Florida: CRC, 1997, p.19-29.

KIMURA, M; RODRIGUEZ-AMAYA, D.B. A scheme for obtaining standards and HPLC quantification of leafy vegetable carotenoids. Food chemistry. v.78, n.3, p. 389-398, 2002.

KHACHIK, F.; BEECHER, G.R.; GOLI, M.B. Separation, identification, and quantification of carotenoids in fruits, vegetables and human plasma by high performance liquid chromatography. Pure and Applied Chemistry. v. 63, n.1, p. 71-80, 1991.

KHACHIK, F. et al. Chemistry, distribuition, and metabolism of tomato carotenoids and their impact on human health. Experimental Biology and Medicine. v. 227, n.10, p. 845$851,2002$.

KRIS-ETHERTON, P.M. et al. Bioactive compounds in foods: their role in the prevention of cardiovascular disease and cancer. Americal Journal of Medicine. v. 113, n. 9B, p. 71S88S, 2002.

KWAK, N.; JUKES, D. J. Functional foods. Part 2: the impact on current regulatory terminology. Food Control. v. 12, p. 109-117, 2001.

LEVY, J.; SHARONI, Y. The Functions of Tomato Lycopene and Its Role in Human Health. HerbalGram - Journal of the American Botanical Council, v. 62, p. 49-56, 2004.

LIVNY, O., et al. Lycopene inhibits proliferation and enhances gap-junction communication of KB-1 human oral tumor cells. Journal of Nutrition. v. 132, n. 12, p. 3754-3759, 2002. 
LYCOPENE. Monograph. Alternative Medicine Review. v. 8, n. 3, p. 336-342, 2003.

MACHADO, C. X. Tomate - o papel do licopeno na proteção antioxidante. 2005. $13 \mathrm{f}$. Monografia. Universidade Federal do Rio Grande do Sul, 2005.

MICHAUD, D.S. et al. Intake of specific carotenoids and risk of lung cancer in 2 prospective US cohorts. American Journal of Clinical Nutrition. v.72, n.4, p. 990-997, 2000.

MIRANDA, K. F. Estudo da concentração de licopeno por ultrafiltração a partir de suco de melancia (Citrullus vulgaris Schard). 2005. 175f. Dissertação (Mestrado em Tecnologia de Alimentos) Universidade Estadual de Campinas (UNICAMP), Campinas, 2005.

MONTERO, M. Los radicales libres y las defensas antioxidantes: revisión. Anales de la Facultad de Medicina, v. 57, n.4, p. 278-281, 1996.

MORAES, F. P.; COLLA, L. M. Alimentos Funcionais e Nutracêuticos: Definições, Legislação e Benefícios à Saúde. Revista Eletrônica de Farmácia, v. 3, n.2, p. 109-122, 2006.

MORAES, V. H. F. Alegações sobre as propriedades funcionais do licopeno: um estudo com consumidores do município de Campinas/SP. 2007. 118f. Dissertação (Mestrado em Alimentos e Nutrição - área de consumo e qualidade de alimentos). Universidade Estadual de Campinas (UNICAMP), Campinas, 2007.

MORITZ, B.; TRAMONTE, V. L. C. Biodisponibilidade de Licopeno. Revista de Nutrição, v. 19, n. 2, p. 265-273, 2006.

NIIZU, P. Y. Fontes de carotenóides importantes para a saúde humana. 2003. 87f. Dissertação (Mestrado em Ciência e tecnologia de Alimentos). Universidade Estadual de Campinas (Unicamp), Campinas, 2003.

OLSON, J.A. Carotenoids and human health. Archivos Latinoamericanos de Nutricion. v. 49, supl. 1, p. 7S - 11S, 1999.

PADULA, M; RODRIGUEZ-AMAYA, D.B. Changes in individual carotenoids and vitamin C on processing and storage of guava juice. Acta Alimentaria. v. 16, p. 209-216, 1987. 
PAPAS, A.M. Diet and antioxidant status. Food and Chemical Toxicology. v.37, p. 37:9991007, 1999.

PARKER, R.S. et al. Bioavailability of carotenoids in human subjects. Proceedings of the Nutrition Society. v.58, n.1, p. 155-162, 1999.

PORCU, O.M. Fatores que influenciam na composição de carotenóides em goiaba, acerola, pitanga e seus produtos processados. 135f. Tese (Doutorado) - Faculdade de Engenharia de Alimentos, Universidade Estadual de Campinas, Campinas, 2004.

RAO, A. V. Lycopene, Tomatoes, and the Preventions of Coronary Hearth Disease. Experimental Biology and Medicine. v. 227, p. 909-913, 2002.

RAO, A. V.; AGARWAL S. Role of Antioxidant Lycopene in Cancer and Heart Disease. Journal of the American College of Nutrition, v. 19, n. 5, p.563-569, 2000.

RAO, A.V.; WASEEM, Z.; AGARWAL, S. Lycopene contents of tomatoes and tomato products and their contribution to dietary lycopene. Food Research International. v.31, p. 737-741, 1998.

RODRIGUEZ-AMAYA D.B. Latin American food sources of carotenoids. Archivos Latinoamericanos de Nutrición, v.49, n.1, p.74-84, 1999.

RODRIGUEZ-AMAYA, D. B. Brazil: a bounty of carotenoid source. Sight and life newsletter, v.4, p.3-9, 2002.

SERRA, S. R.; CAMPOS, R. G. Efeito Protetor do Licopeno. Revista Brasileira de Nutrição Clínica,, v. 21, n. 4, p. 326-332, 2006.

SGARBIERI, V.C.; PACHECO, M.T.B. Revisão: alimentos funcionais fisiológicos. Brazilian Journal of Food Technology, v.2, n.1/2, p. 7-19, 1999.

SHAMI, N. J. I. E.; MOREIRA, E. A. M. Licopeno como agente antioxidante. Revista de Nutrição, v. 17, n. 2, p. 227-236, 2004.

SHI, J; LE MAGUER, M. Lycopene in tomatoes: chemical and physical properties affected by food processing. Food Science and Nutrition, v.40, n.1, p. 1-42, 2000. 
SILER, U. et al. Lycopene effects on rat normal prostate and prostate tumor tissue. Journal of Nutrition. v. 135, n. 8, p. 2050S- 2052S, 2005.

SOUZA, P. H. M.; SOUZA NETO, M. H.; MAIA, G. A. Componentes funcionais nos alimentos. Boletim da SBCTA. v. 37, n. 2, p. 127-135, 2003.

SPEISKY, H. C.; JIMÉNEZ, I. T. Radicales libres y antioxidantes en la prevención de enfermedades III: evidencias clínico epidemiológicas de los riesgos y beneficios asociados al consumo de antioxidantes en la prevención de enfermedades cardiovasculares. Revista Chilena de Nutricion. v. 27, n. 3, p. 314-325, 2000.

STAHL, W.; SIES, H. Uptake of lycopene and its geometrical isomers is greater from heat-processed than from unprocessed tomato juice in humans. Journal of Nutrition. v.122, n.11, p.2161-2166, 1992.

TANG, L., et al. Lycopene inhibits the growth of human androgen-independent prostate cancer cells in vitro and in BALB/c nude mice. Journal of Nutrition. v.135, n.2, p. 287290, 2005.

TAVARES, C.A; RODRIGUEZ-AMAYA, D.B. Carotenoid composition of brazilian tomatoes and tomato products. Lebensmittel wissenschaft und technologie. v. 27, p. 219-224, 1994.

TIUZZI, M. Licopeno e câncer: bases biomoleculares. 2008. 27f. Monografia (Pós Graduação em Nutrição Clinica). Ganep, 2008.

TSUGANE, S. Salt, salted food intake, and risk of gastric cancer: epidemiologic evidence. Cancer Science. v. 96, n.1, p. 1-6, 2005.

UNLU, N.Z. et al. Lycopene from heat-induced cis-isomer-rich tomato sauce is more bioavailable than from all-trans-rich tomato sauce in human subjects. British Journal of Nutrition. v.98, p. 140-146, 2007.

WILLCOX, J.K.; CATIGNANI, G.L.; LAZARUS, S. Tomatoes and cardiovascular health. Critical Reviews in Food Science and Nutrition. v.43, n.1, p. 1-18, 2003.

XIANQUAN, S., et al. Stability of Lycopene During Food Processing and Storage. Journal of Medicinal Food. v. 8, n. 4, p. 413-422, 2005. 
YEUM, K. J. et al. Biomarkers of antioxidant capacity in the hydrophilic and lipophilic compartments of human plasma. Archives of Biochemistry and Biophysics. v. 430, n.1, p. 97-103, 2004.

YU, T-W., ANDERSON, D. Reactive oxygen species-induced DNA damage and its modification: a chemical investigation. Mutation Research. v.379, n.2, p.201-210, 1997. 